\title{
DaVId MarÇAL Prémio Químicos Jovens / Gradiva 2010
}

\author{
Entrevista conduzida por Carlos Baleizão ${ }^{1}$ e \\ Frederico FerReira ${ }^{2}$
}

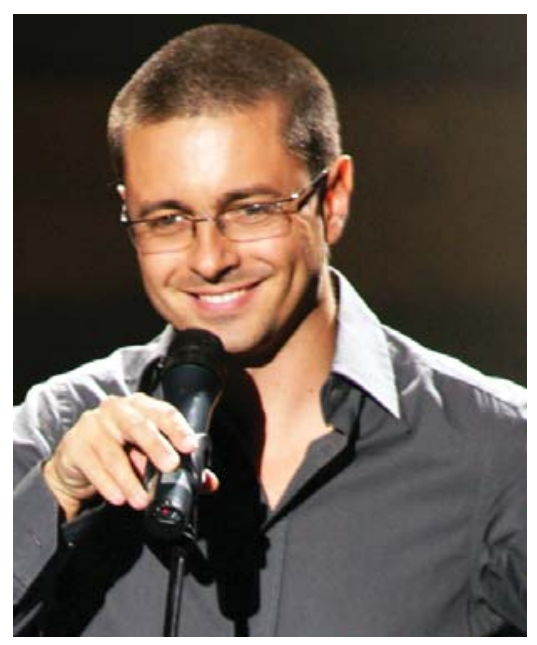

\begin{abstract}
O
Dr. David Marçal foi vencedor ex-equo do Prémio Químicos Jovens / Gradiva 2010, com um artigo intitulado "O Sindicato das Proteínas". A entrevista teve lugar na sede da Associação Viver a Ciência, em Lisboa, na qual o David é colaborador e onde passa parte do seu tempo a conjugar divulgação científica com humor.
\end{abstract}

CB: Qual foi a motivação para concorrer ao Prémio Químicos Jovens / Gradiva 2010?

DM: Na altura em que estava a escrever a minha tese de doutoramento comecei a publicar pequenos textos no blogue "DE RERUM NATURA" que contavam a história do meu doutoramento. Quando vi o regulamento do prémio pensei que podia utilizar esse material para concorrer. E como estou neste momento ligado à comunicação de ciência, achei que fazia sentido.

FF: Transpor a ciência que se faz nos nossos laboratórios em divulgação científica é um desafio reconhecido por todos. Quais as maiores dificuldades que encontraste em transformar Ciência de bancada em divulgação?

DM: A principal dificuldade foi o tema ser o meu próprio trabalho. Já tinha escrito para o Público sobre o trabalho de outras pessoas, mas sobre o meu trabalho é muito mais difícil. Estou tão envolvido e tudo me parece tão lógico, que por vezes tenho de parar e dar um passo atrás para conseguir explicar as coisas de um modo compreensível para todos. Eu

CQFM/IST, carlos.baleizao@ist.utl. pt 2 IBB-IST, frederico.ferreira@ist.utl.pt trabalhei com proteínas, e quando fiz um estágio no Público no âmbito do programa "Cientistas na Redacção", uma estagiária de jornalismo perguntou-me o que era uma proteína. Eu tinha tanta coisa para dizer sobre o que era uma proteína, que simplesmente a confundi. Nesse momento percebi como é difícil explicar de uma forma simples o nosso trabalho na Ciência, pois estamos emocionalmente ligados e rejeitamos qualquer tipo de simplificação. Para concluir a resposta, o que fiz em relação ao texto do prémio foi contar pequenas histórias, sem tentar ser sistemático.

CB: O que achas da forma como a ciência e a divulgação científica é tratada nos meios de comunicação (jornais, TV, rádio)? O trabalho é de qualidade ou ainda temos um caminho a percorrer?

DM: Temos um caminho a percorrer, a questão é por quem. Em relação à qualidade existe uma diferença quando o trabalho é realizado por jornalistas especialistas em ciência ou por jornalistas generalistas que pegam num tema científico. Os primeiros fazem um trabalho de elevada qualidade, os outros nem sempre. Mas infelizmente existe uma tendência a nível mundial para a redução das redacções de ciên- cia e dos jornalistas dedicados exclusivamente à ciência. Esta tendência é bem visível nos jornais portugueses. Embora esta situação seja um problema, também é uma oportunidade para os cientistas se envolverem cada vez mais na divulgação de ciência, principalmente através das redes sociais e blogues.

FF: Como pode um cientista que nunca escreveu para um órgão de comunicação social, melhorar a sua escrita de divulgação?

DM: As pessoas ou se sentem motivadas a escrever ou o melhor é nem começarem. Mas o mais importante é os cientistas perceberem que têm de explicar o que fazem a pessoas que não são especialistas. Os gabinetes de comunicação das Universidades também podem ter um papel importante, se funcionarem como pontes entre os meios de comunicação e os cientistas.

FF: Achas que temos uma sociedade cada vez mais de conhecimento e por isso é mais fácil fazer divulgação científica?

DM: Penso que temos uma sociedade um pouco esquizofrénica, que por um lado reconhece a importância da ciên- 
cia e se vira para ela para melhorar a sua qualidade de vida, mas ao mesmo tempo vacila no reconhecimento da importância dos cientistas. Outro equívoco é a não distinção entre investigação fundamental e aplicada, e a falta de consciência da importância da primeira para que a segunda tenha sucesso.

CB: Neste momento és investigador de pós-doutoramento no Instituto de Medicina Molecular da Universidade de Lisboa, no Museu da Ciência da Universidade de Coimbra e na Associação Viver a Ciência com um projecto intitulado "Comunicação e divulgação de ciência, recorrendo ao teatro e ao humor". Fala-nos um pouco dos objectivos iniciais e dos resultados que já alcançaste.

DM: Os objectivos são criar veículos de comunicação de ciência que sejam apelativos para o público em geral, recorrendo ao teatro e ao humor. Comecei por criar vários espectáculos para a Noite dos Investigadores 2009 com abordagens diferentes, em que os objectivos são comunicar ciência envolvendo investigadores. Um dos projectos chama-se "Os Cientistas de Pé", é um grupo de stand-up comedy com cientistas das mais variadas áreas que falam de temas científicos com ligação à vida quotidiana numa perspectiva cómica. Outro espectáculo chama-se "Stupid Design" e foi criado para o Museu da Ciência da Universidade de Coimbra. É um monólogo humorístico interpretado por um actor profissional, que satiriza as teorias do Inteligent Design, que tentam mascarar o criacionismo como Ciência. Este espectáculo foi desenvolvido em paralelo com outro chamado "Nascer da Evolução" cujo tema é o desenvolvimento da resistência aos antibióticos pelas bactérias. Nestes espectáculos, que são produzidos profissionalmente, tendo encenador e actores profissionais, a participação dos cientistas é feita através de vídeo ou por falsas perguntas do público ao conferencis-

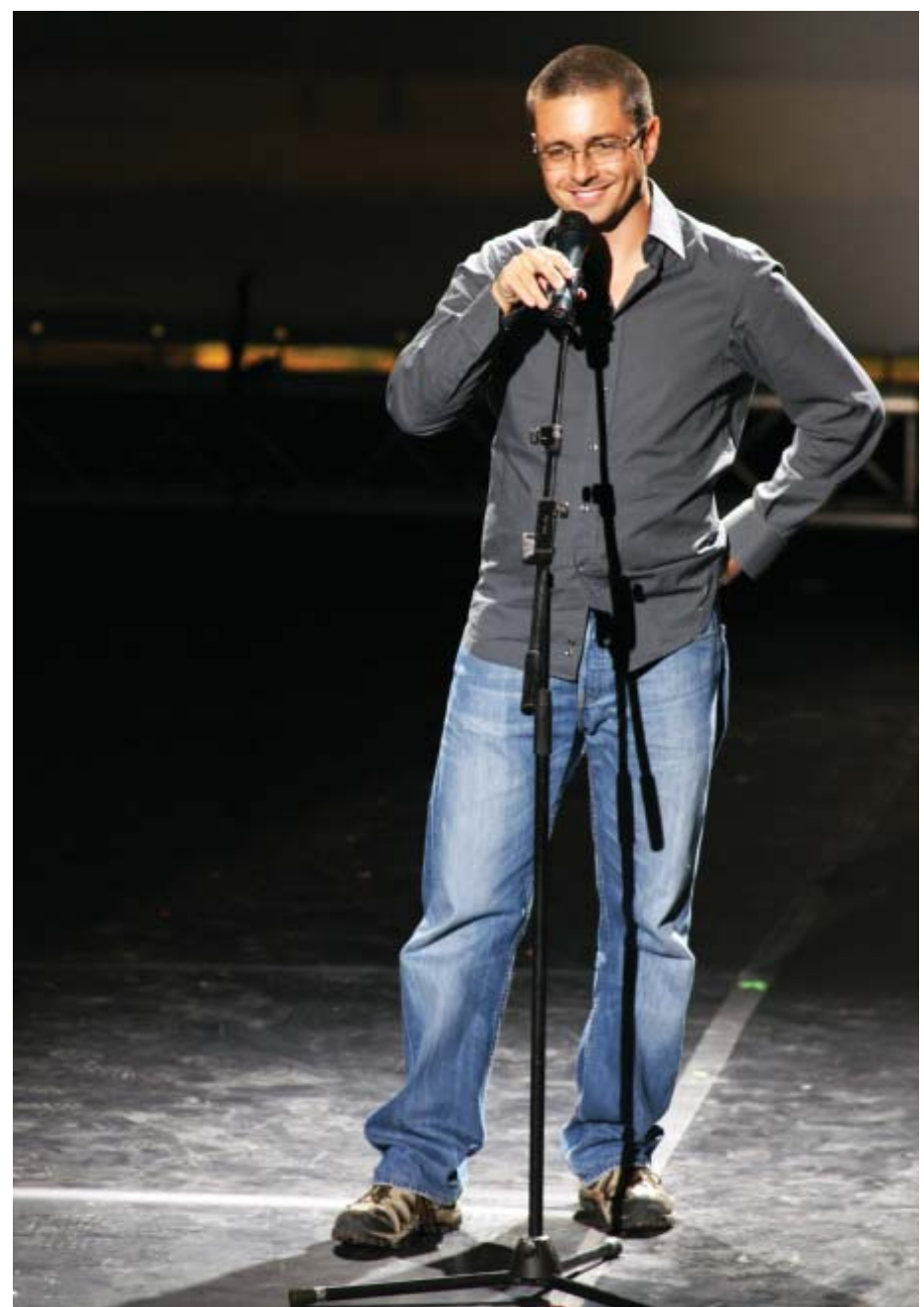

David Marçal num dos espectáculos "Os Cientistas de Pé" ta. No total, foram efectuadas entre 2009 e 2010, 27 espectáculos com 42 investigadores envolvidos.

CB: Que tipo de público costuma assistir a estes espectáculos e que feedback costumas ter?

DM: O público é muito variado, pois já fizemos espectáculos nos mais diversos contextos. Os "Cientistas de Pé" já actuaram na ILGA, na Sociedade de Instrução Guilherme Cossoul, no anfiteatro ao ar livre da Gulbenkian para mais de 1000 pessoas (na Noite Europeia dos Investigadores), no Teatro Municipal de Bragança, etc. O público mais difícil foi no Open Day da Lx Factory, talvez mais eclético e distante da ciência, levou mais tempo a ser cativado. Em relação ao feedback, esse tem sido sempre positivo.

FF: Também és colaborador no Inimigo Público (nota: suplemento satírico colado à actualidade, distribuído com o jornal Público), com alguns textos a utilizarem linguagem e conceitos científicos. Até que profundidade vais em relação aos conceitos utilizados?

DM: Já tive uma preocupação maior em ir a uma profundidade grande, mas no Inimigo Público o principal objectivo é fazer humor e as pessoas lêem o jornal por causa disso. Divulgar e comunicar ciência vem depois. O texto pode ser apenas uma forma de gerar interesse por um determinado tema científico ou envolver conceitos mais aprofundados. Por exemplo, já escrevi um texto algo extenso sobre a relação entre a segunda lei da termodinâmica e a tendência para ocorrer corrupção nas autarquias. Mas também pode ser uma ideia simples, como que a extensão da plataforma continental portuguesa fará baixar a dívida pública por metro quadrado.

CB: Fazes da criatividade um dos pilares do teu trabalho. A criatividade treina-se?

DM: O mais importante é não asfixiála. Treinar a criatividade é exercê-la, arriscar, experimentar, não ter medo de falhar.

FF: Quais as diferenças entre a criatividade científica e a criatividade humorística? 


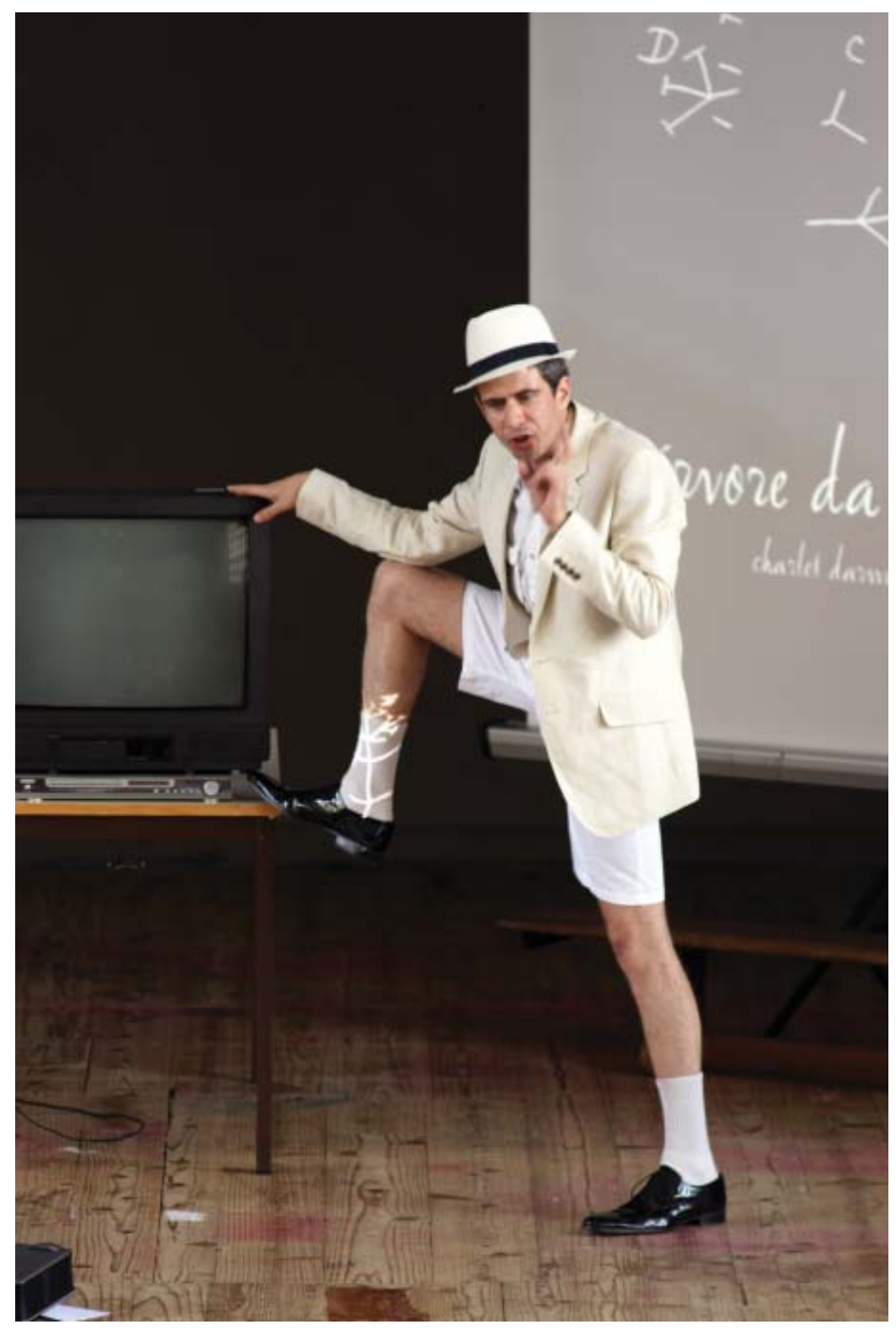

Espectáculo "Stupid Design"

DM: Para mim uma diferença prática é a duração dos ciclos. Quando estamos a fazer investigação, os ciclos de exposição pública são mais longos. Apesar de termos resultados diários e podermos fazer uma avaliação semanal ou mensal, a apresentação do trabalho faz-se num congresso ou quando publicamos o artigo. No humor, e no caso particular do Inimigo Público, o ciclo é semanal. Na Terça começamos a escrever, à Sexta é publicado e na semana seguinte já não nos lembramos do que é que escrevemos. No entanto algo liga a criatividade científica à criatividade humorística, que é a necessidade de termos um olhar diferente e um pensamento divergente em relação a um determinado conceito já estabelecido.

CB: O teu percurso após licenciatura é muito peculiar: começaste pela indústria farmacêutica, nomeadamente como investigador na Hovione, de seguida voltaste à Universidade para o doutoramento e agora estás na divulgação de Ciência. Este percurso foi planeado previamente na medida que querias ter um percurso diversificado, ou foste aceitando os novos desafios que iam surgindo?

DM: Não foi planeado. O que existe de comum a todo o percurso é a Ciência. Acabou por resultar numa diversidade de experiências bastante grande. $O$ contacto com a indústria farmacêutica permitiu-me conhecer a investigação aplicada e o desenvolvimento de processos. O doutoramento permitiu-me regressar à investigação fundamental, na qual me revejo mais. A divulgação científica surge de um percurso que sempre tive em paralelo com a investigação. Desde 2003 que escrevo para o Inimigo Público, e a dada altura apercebi-me que ia escrever essencialmente sobre temas científicos, fazendo sátira usando conceitos e lin- guagem científica. E acaba por surgir naturalmente no final do doutoramento a opção de trabalhar a tempo inteiro na comunicação de ciência.

FF: Mas a tua escrita remonta a antes de 2003, quando participavas na revista "Fórum Estudante".

DM: Sim. Comecei a escrever na "Fórum Estudante" em 1993, e na altura existia espaço para escrever sobre os mais variados temas e uma grande abertura também quanto aos formatos. Desde logo comecei por escrever textos de cariz humorístico e também foram aí as minhas primeiras experiências a escrever sobre temas científicos.

CB: Terminaste o doutoramento em 2008 no ITQB. Durante esse período, qual a maior dificuldade que tiveste de ultrapassar?

DM: A incerteza dos resultados, e se no final teria volume e qualidade suficiente para escrever uma tese. Digamos que estava num dilema entre a ambição do que se procura e o realismo do que é possível fazer. Mas ao mesmo tempo foi importante aprender a fazer esse equilíbrio e a tomar decisões.

\section{FF: E o que te deu mais prazer?}

DM: Quando acabou e obtive a estrutura da minha proteína, pois foi muito difícil (risos). Mas também a autonomia que se ganha e a capacidade de tomar decisões.

FF: Ao longo do teu doutoramento estiveste períodos fora de Portugal, nomeadamente França e Inglaterra. Quais as diferenças que encontraste e que lições trouxeste?

DM: Estes países continuam a ter meIhores condições para fazer investigação. Não me refiro somente a recursos financeiros e meios técnicos, que são uma diferença importante, mas também de cultura organizacional. No sistema inglês as pessoas são mais responsabilizadas, há mais mobilidade profissional, menos endogamia (e não é bem vista), o que tem um efeito positivo na qualidade da ciência produzida. As estruturas de apoio são 


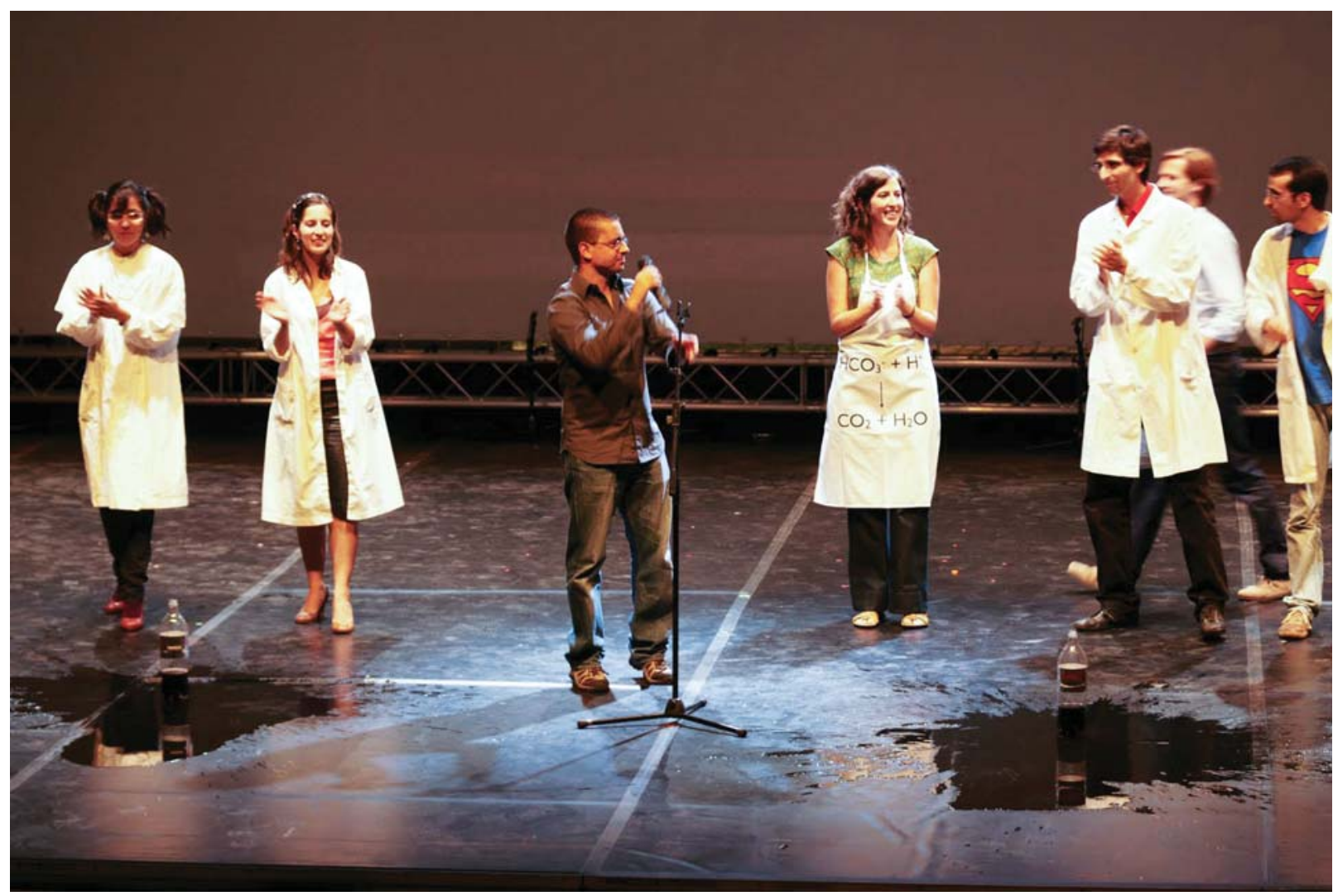

Alguns participantes do espectáculo "Os Cientistas de Pé"

mais abundantes e estão próximas, existindo por exemplo mais técnicos de laboratório. Com o que eles não conseguem competir é com a gastronomia, o clima e o sex appeal dos portugueses!

CB: O doutoramento é o início de uma carreira exclusiva a fazer investigação, ou pode ser uma ferramenta para ser utilizada em outras áreas?

DM: O doutoramento é uma ferramenta que pode ser rentabilizada noutras áreas para além da investigação, como na comunicação de ciência, gestão de ciência e outras carreiras de apoio à investigação que são muito necessárias. Por exemplo, angariar dinheiro é algo muito específico e muito complicado. Estas carreiras de apoio à investigação podem permitir que os investigadores dediquem mais tempo ao seu trabalho científico. Outro percurso possível é o empreendedorismo. Depende muito da motivação pessoal, mas penso que há alternativas à investigação que não são um subaproveitamento do doutoramento.

FF: Há pouco referias que o doutoramento nos dá uma relação privilegiada com o conhecimento...

DM: A grande vantagem do doutoramento é ter uma relação diferente com o conhecimento. O conhecimento passa a ser visto como algo plástico, que se constrói, e não como uma coisa estática, escrita na pedra. E é essa relação com o conhecimento que é para mim a grande vantagem de um doutoramento. Por isso é que é importante que os professores universitários tenham uma actividade de produção científica, para que possam transmitir essa dimensão dinâmica do conhecimento.

CB: Que conselho deixas aos jovens que acabaram recentemente os seus cursos e estão a começar no mundo da investigação?
DM: Que escolham uma área que realmente gostem, não esquecendo que a escolha do orientador também é importante. Considerem fazer uma pausa para escolher caso estejam indecisos, pois o doutoramento é muito exigente e se não houver uma motivação muito grande tudo será mais difícil. Também é uma oportunidade para ir para fora, em geral numa altura da vida em que isso é favorável.

CB: Terminámos a entrevista. Obrigado pelo tempo concedido e boa sorte para o futuro.

\section{NotA:}

Para mais informações sobre os espectáculos referidos ao longo da entrevista podem consultar os seguintes links:

http://cientistasdepe.blogspot.com/ http://dequefalamosquandofalamosdecientistas.blogspot.com/ http://nascerdaevolucao.blogspot.com/

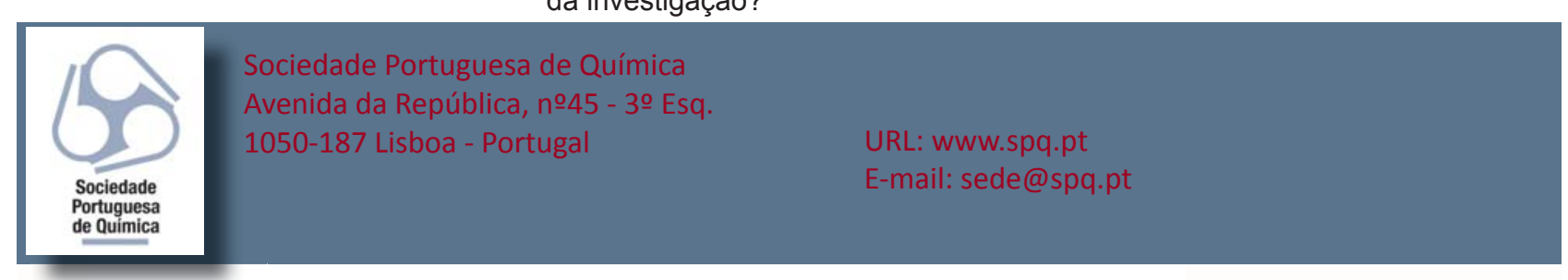

